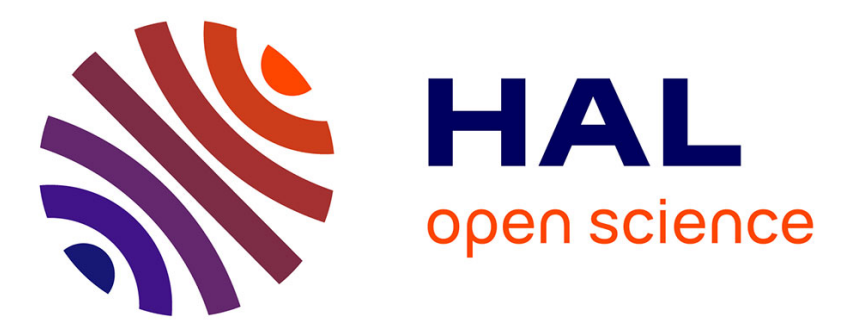

\title{
Pseudo-static scaled-down experiments on dry stone retaining walls: preliminary implications for the seismic design
}

Nathanaël Savalle, Eric Vincens, Stephane Hans

\section{- To cite this version:}

Nathanaël Savalle, Eric Vincens, Stephane Hans. Pseudo-static scaled-down experiments on dry stone retaining walls: preliminary implications for the seismic design. Engineering Structures, 2018, 171, pp.336-347. 10.1016/j.engstruct.2018.05.080 . hal-03022213

\section{HAL Id: hal-03022213 \\ https://hal.science/hal-03022213}

Submitted on 24 Nov 2020

HAL is a multi-disciplinary open access archive for the deposit and dissemination of scientific research documents, whether they are published or not. The documents may come from teaching and research institutions in France or abroad, or from public or private research centers.
L'archive ouverte pluridisciplinaire HAL, est destinée au dépôt et à la diffusion de documents scientifiques de niveau recherche, publiés ou non, émanant des établissements d'enseignement et de recherche français ou étrangers, des laboratoires publics ou privés. 


\title{
Pseudo-static scaled-down experiments on dry stone retaining walls: preliminary implications for the seismic design$$
\text { DOI : 10.1016/j.engstruct.2018.05.080 }
$$ \\ This manuscript version is made available under the CC-BY-NC-ND 4.0 license \\ http://creativecommons.org/licenses/by-nc-nd/4.0/
}

\author{
Nathanael Savalle ${ }^{\mathrm{a}}$, Eric Vincens ${ }^{\mathrm{a}, *}$, Stphane Hans ${ }^{\mathrm{b}}$ \\ ${ }^{a}$ University of Lyon, LTDS, UMR CNRS 5513, École centrale de Lyon, Écully, France \\ ${ }^{b}$ University of Lyon, LTDS, UMR CNRS 5513, École Nationale des Travaux Publics de l'État, Vaulx-en-Velin, France
}

\begin{abstract}
Dry stone retaining walls (DSRWs) are vernacular structures which can be found all over the world. Most of them have been built in the $19^{\text {th }}$ century but they can be as old as two hundred years. Because of decades of neglect, many of these walls are highly damaged; however, in the absence of national rules for this peculiar heritage, any intervention on these constructions is made difficult. A number of former studies in France have tried to settle the bases for a standard aimed at designing slope DSRWs. This paper complement those works in order to give clues for a seismic design of slope DSRWs following the simplified approach proposed by the Eurocode 8 and denoted pseudo-static approach.

Firstly, scaled-down experiments have been carried out using a mock-up composed of a wall made of clay bricks retaining a sandy backfill. This mock-up was then tilted and the characteristics of the system at failure were reported and analysed. A particularity of failure in DSRWs is that the failure surface crosses the wall leaving a part of it intact. Secondly, an analytic method based on the limit equilibrium using the Coulomb wedge theory has been designed to predict the tilting angle and validated on the basis of these experimental results. Finally, some preliminary implications for the seismic design of DSRWs have been proposed for walls built in moderate seismicity areas which is typical of mainland France. In low seismicity zones, the extra width required to bear the seismic motion does not exceed $25 \%$ of the width identified through the static design. Results are also given for more critical cases associated to zones of higher seismicity as well as for different wall configurations.
\end{abstract}

Keywords: masonry, seismic, scaled-down tests, slope

\section{Introduction}

Dry stone retaining walls (DSRWs) are vernacular structures made of rubble stones collected on site and that are hand-assembled without mortar. The weight of the wall, the friction between blocks as well as the peculiar arrangement of the blocks ensure its stability. Despite looking simple, the construction process requires a definite know-how to minimize the porosity within the wall and to achieve a specific arrangement of the blocks able to provide a three-dimensional overall bond strength to the structure.

For centuries, these structures have been used for slope stabilisation against erosion in mountain areas. They have allowed agricultural or wine-growing activities on the artificial terraces and the development of transportation networks in hardly accessible regions. Their intrinsic architectural and

\footnotetext{
${ }^{*}$ Corresponding author. Tel.: +33472186221.

Email address: eric.vincens@ec-lyon.fr (Eric Vincens)
}

landscape quality explain why some of the emblematic sites where this masonry heritage can be found have been inscribed as a part of the World Heritage, UNESCO (e.g. "Valley of Douro", Portugal; "Serra de Tramuntana", Majorca island Spain"; Lavaux terraces", Switzerland). Recently, some local authorities have envisioned this dry stone heritage as an asset for the economic development of remote territories as a new tourism offer (e.g. "Ruta de pedra en sec", Majorca island, Spain).

Nevertheless, this heritage is very often highly damaged due to decades of neglect. The rehabilitation of these structures remains a significant issue in a context where repairs must be processed without the guidance of national standards that are unavailable in most European countries.

However, some studies have tried to restore the knowledge related to the behaviour of the DSRWs. The first study has been developed in 1834 by Sir John Burgoyne [1]. He studied 
the impact of the geometry of the walls on their stability confirming the state of the art of this heritage. For the same cross-sectional area, the batter of the external face of the wall gives extra resistance whereas the batter of the internal face gives no added resistance. After this first referenced study, Cooper [2] brought to light the three possible failures for a slope DSRW: sliding, overturning and bulging. The sliding and overturning modes of failure are two plane deformation modes of failure in which the failure surface splits the system into two parts: a lower part of the wall that remains intact and that almost does not move during failure and an upper part that falls apart. The bulging mode of failure is either a true three-dimensional mode of failure that is observed for walls built on compressible soils or a plane deformation mode of failure.

Lately, Villemus [3], Colas [4] and Mundell [5] have developed different analytic design methods for plane DSRWs. In particular, Villemus used a method based on the Coulomb wedge to predict the sliding and overturning mode of failure while Colas used a yield design method. These different approaches were validated on a set of full-scale experiments. In a more different way, Mundell used also a limit equilibrium method based on Coulomb's earth pressure where the stability of the wall was checked at each layer of stones in the wall. This programm succeeded in reproducing full-scale experiments where the bulging phenomenon appeared. Recently, numerical studies were performed to model the static behaviour of DSRWs, including the finite element method (FEM) [6], the discrete element method (DEM) [7] or a mixed DEM-FEM approach [8-10]. Finally, more recent studies have allowed to explore the static three-dimensional failure of DSRWs induced by a concentrated load like a vehicle at the surface of the backfill in the case of highway DSRWs [11, 12].

However, most of the DSRWs are built in regions where the seismic risk is critical (e.g. in France, Greece, Italy, Portugal, Spain). Even if Eurocode 8 [13] gives a guidance for the design of retaining walls in seismic zones, specificities of DSRWs are not addressed in this standard.

The first works that have taken into account the effect of seismic action on retaining walls were carried out by Mononobe and Okabe [14, 15]. The pseudo-static method (known as Mononobe-Okabe method) they designed for this purpose is the one recommended by Eurocode 8 [13]. Further developments have been made by other authors [16, 17] to take into account the vertical acceleration and the direct effect of the seismic action on the wall. However, the pseudo-static approach which is a simplified approach for the dynamic problems has some limitations and leads to uncorrect results. Indeed, for high seismic accelerations (above $0.3 \mathrm{~g}$ ), this method greatly over-estimates the seismic action. According to Baziar [18], the estimate of the seismic action in the pseudo-static case can reach a value five times bigger than the estimate using a pseudo-dynamic method. In the pseudo-dynamic approach by Baziar and other authors [18-20], the undulatory characteristic of the seismic motion is taken into account to improve the accuracy of the seismic design method.

As a first step to address the specific design of slope DSRWs, a pseudo-static approach of the seismic problem is herein proposed. First, a set-up including a brick wall and a backfill for experiments is presented. Then, a parametric study addressing the influence of the wall geometry on the seismic resistance of the wall-backfill system was carried out. In a second part, an improved analytical method based on the Coulomb wedge theory is presented and then validated on the basis of the experiences. Finally, some preliminary implications are given for the seismic design of slope DSRWs.

\section{Scaled-down model and case studies}

\subsection{Scaled-down model}

\subsubsection{General characteristics}

For the sake of simplicity, the experimental tests have been carried out on a scaled-down model (Figure 1) composed of a $10 \mathrm{~cm}$ high retaining brick wall loaded by a backfill. The length of the wall has been chosen equal to $40 \mathrm{~cm}$ to ensure a plane deformation state behaviour (and to limit side effects on the wall behaviour). This wall and the backfill were placed in a container of $40 \mathrm{~cm}$ length, $40 \mathrm{~cm}$ width and $25 \mathrm{~cm}$ high. A pre-design of the retaining wall has enabled us to point out that the failure surface within the backfill does not intercept the lateral walls of the container (Figure 2).

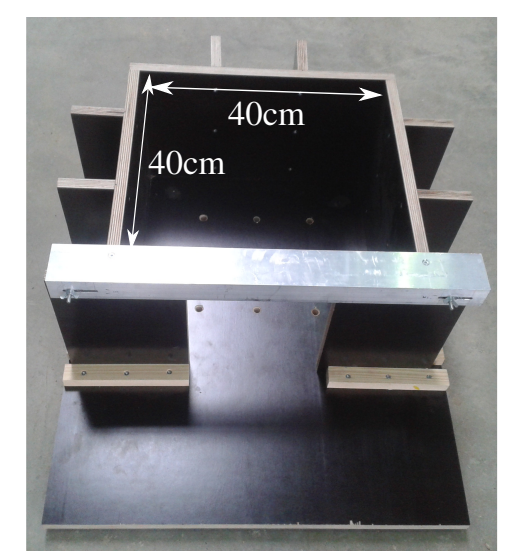

Figure 1: Container. The length of the wall (placed in the aperture) is variable (maximum length $=40 \mathrm{~cm}$ ).

The retaining wall was made of small clay bricks of dimensions: $33 \mathrm{~mm}^{*} 17 \mathrm{~mm} * 11 \mathrm{~mm}$ (length*width*height $)=\left(\mathrm{L}^{*} \mathrm{l}^{*} \mathrm{~h}\right)$. The backfill was composed of Hostun sand and the backfill surface was built horizontal. Some sand was poured and glued on the surface floor of the container in order to obtain a friction angle at this boundary similar to the internal friction angle of the sand. For convenience, the lateral walls of the container were made with a plywood panel and no peculiar treatment 


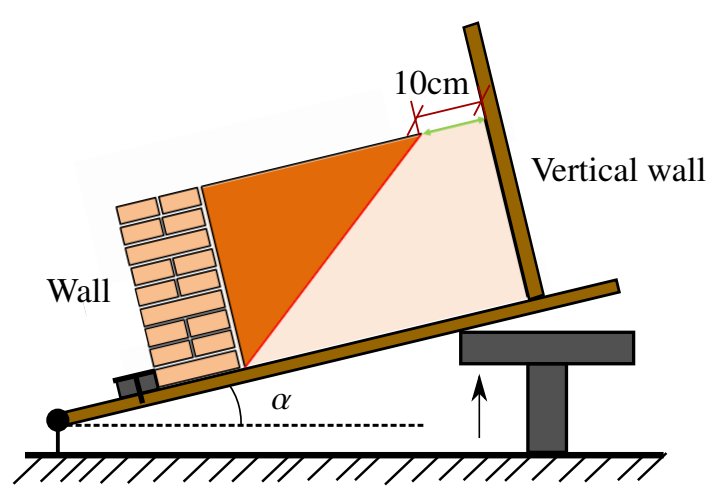

Figure 2: Cross-section view of the container and the backfill-wall system; gap of $10 \mathrm{~cm}$ between the container vertical back wall and the failure surface within the backfill; a piece of wood fixed to the container floor blocks the translational movement of the first row of bricks.

was added to limit friction between the lateral walls of the container and the backfill.

\subsubsection{Properties of the materials}

The unit weight of the wall (including pores between blocks) was $14.4 \pm 0.27 \mathrm{kN} / \mathrm{m}^{3}$. The friction angle between blocks has been evaluated to $32 \pm 2^{\circ}$ in a previous work[12]. The backfill was composed of Hostun sand: $\mathrm{D}_{50}=0.37 \mathrm{~mm}, \mathrm{D}_{10}=0.2 \mathrm{~mm}$, $\mathrm{e}_{\max }=1.041$ and $\mathrm{e}_{\min }=0.648$ [21]. To create the backfill, the sand was poured from a zero drop height in order to obtain the loosest state for the material. In fact, the experimental relative density was found to be equal to $4 \%$, which corresponds to a unit weight of $13.15 \pm 0.45 \mathrm{kN} / \mathrm{m}^{3}$. The internal friction angle of Hostun sand in a very loose state has been identified by Flavigny et al. [21] to $32^{\circ} \pm 0.5^{\circ}$ under a confining pressure of 50kPa. A further analysis by Quezada et al. [12] confirmed this value for the same conditions as the test considered in this study, where mean confining pressure is much lower $(0.7 \mathrm{kPa})$.

The friction angle at the interface between wall and sand has been evaluated in this study using a tilting test. In this test, a significant part of the wall including glued blocks has progressively been tilted on a $70 \mathrm{~mm}$ high layer of sand. The interface friction angle corresponds to the angle between the horizontal and the top sand layer when a slide of the glued blocks is triggered. An average value of $22.7 \pm 2^{\circ}$ was obtained by means of eighteen repeated tilting tests.

\subsection{Experimental protocol}

For each experiment, the wall has been firstly erected to reach its final dimension (height $\mathrm{H}$ and width $\mathrm{B}$ ) respecting an alternation of headers and stretchers which is typical of DSRWs (Figure 3) to ensure the overall bond strength of the wall.

Figure 2 indicates that a piece of wood was fixed to the container floor to block the translational movement of the

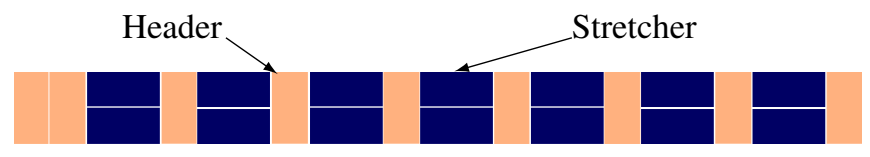

Figure 3: Typical arrangement of bricks. Headers (light color) and stretchers (dark) enable the overall bond strength and the stability of the structure.

first row of the wall bricks. The purpose was to clarify the condition at the boundary for the foundations of the wall (Figure 4). Besides, a space between the retaining wall and the lateral side of the container has been maintained throughout the tests in order to avoid any restriction of the wall movement. A plastic film was added in this space to avoid the seepage of the backfill sand (Figure 4). The container including the wall and the backfill was tilted with a tilting velocity of $0.2^{\circ} \mathrm{s}$. This velocity was provided by a plunge lifting the container (Figure 2). When approaching failure, this velocity was decreased to $0.07^{\circ} / \mathrm{s}$. The critical angle $\alpha$ leading to the wall failure was measured and each tilting test was filmed to identify the mode of failure of the wall.

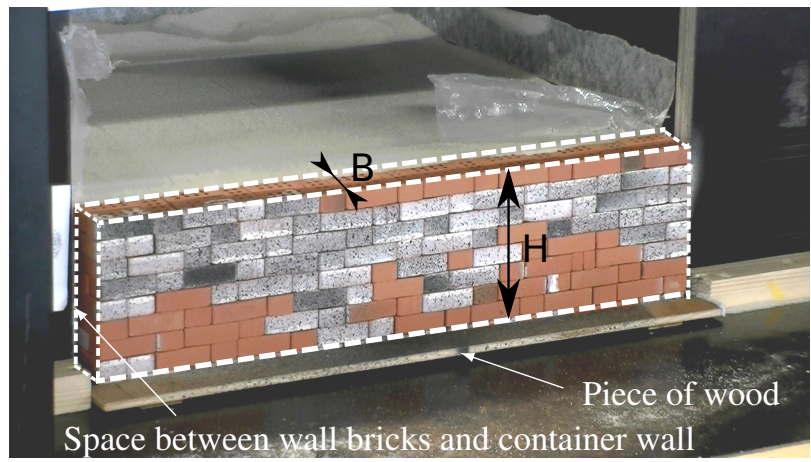

Figure 4: Container with the backfill-wall system, ready for the tilting test. A small piece of wood blocks the translational movement of the first row of clay bricks. Space between retaining wall and lateral container wall; a plastic film prevents the seepage of sand in this space.

\section{Results of experiments}

\subsection{Preliminary tests}

First of all, some repeatability tests have been carried out in order to estimate the quality of the measurements and the biases due to the operator. Indeed, some departure among the results can arise from the process of creation of the wall or from the precision in the installation of the backfill.

For four different slendernesses $(\mathrm{H} / \mathrm{B})$, six identical tests have been carried out. The standard deviation of the tilting angle of failure which tends to decrease with the slenderness was found smaller than $1^{\circ}$. As a consequence, all the next tests that were performed were analysed considering this inherent standard deviation. 


\subsection{Influence of the wall geometry}

\subsubsection{Constant slenderness $H / B$}

In order to investigate the role played by the wall base thickness, different experiments have been performed with retaining walls having the same slenderness (Figure 5).

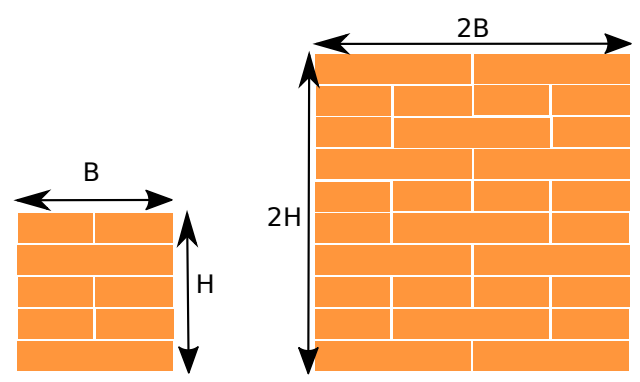

Figure 5: Cross section view of tested walls: two different geometries with a same slenderness $=\mathrm{H} / \mathrm{B}$.

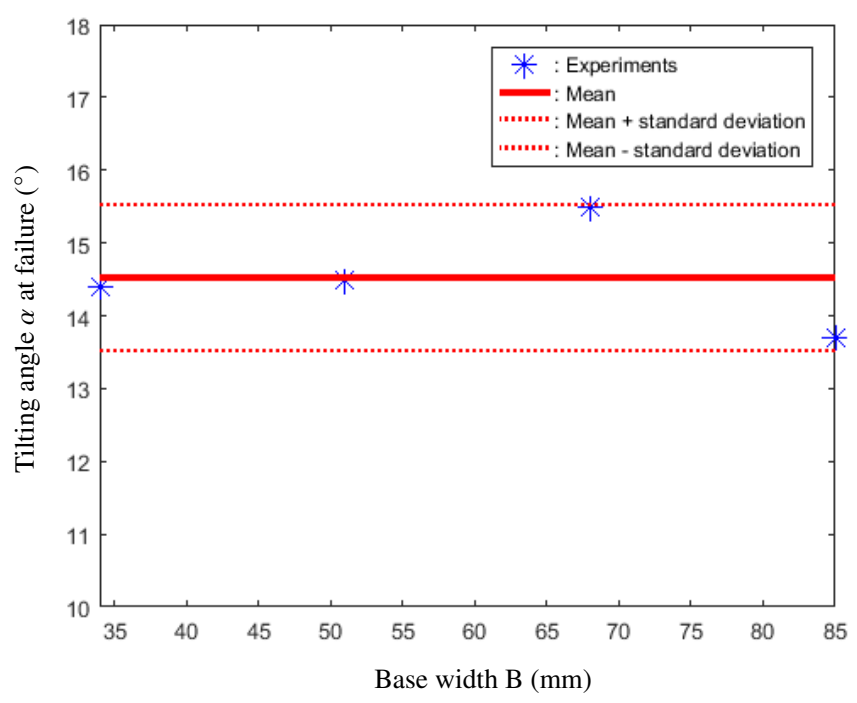

Figure 6: Angle of failure for four tested walls with the same slenderness $\mathrm{H} / \mathrm{B}=2$. The standard deviation $\left(1^{\circ}\right)$ is drawn from the repeatability test.

Some results for the specific slenderness $\mathrm{H} / \mathrm{B}=2$ are given in Figure 6. For a given slenderness, the variation of the angle of failure for the wall was found smaller than the standard variation $\left(1^{\circ}\right)$ identified during the repeatability tests. This means that within the range of studied wall base thicknesses, the slenderness is the main geometrical factor that drives the value of the failure tilting angle. The tests carried out on walls with a slenderness of $\mathrm{H} / \mathrm{B}=8 / 3$ or $\mathrm{H} / \mathrm{B}=10 / 3$ lead to the same conclusions.

\subsubsection{Influence of the slenderness $H / B$}

Even if the typical slenderness of actual dry stone retaining walls spans between 2 and 3, a wider range of values was considered (between 1 and 4) to take into account non conventional geometries that may exist. All the investigated walls hold the same base width B of $34 \mathrm{~mm}$.

The results are given in Figure 7. They indicate that the higher the slenderness is, the smaller the tilting angle at failure is, as expected. Error bars related to repeatability tests are also depicted in Figure 7 .

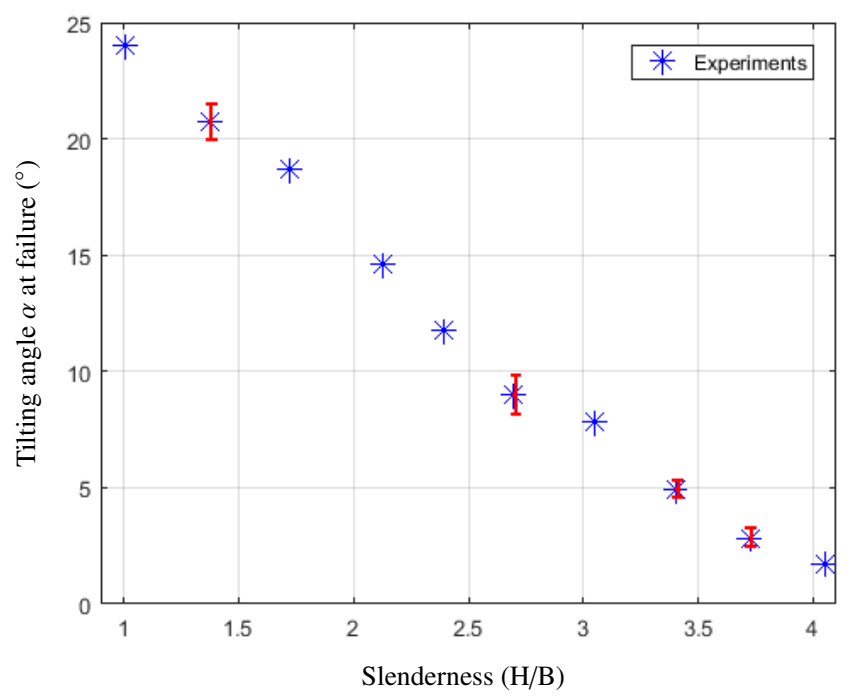

Figure 7: Tilting angle at failure for walls with different slendernesses. Range of values from repeatability tests is also provided.

\subsubsection{Modes of failure}

The video recording of the tests allowed us to observe the two typical modes of failure: overturning (Figure 8) and sliding (Figure 9).

These two modes of failure have already been highlighted by several studies on actual DSRWs [3,-5, 22]. A picture of the mock-up after failure is given in Figure 10. For the case of overturning (Figure 10a), we can see the part of the wall that remained intact after failure. Although only the translation of the first row of bricks was inhibited, no rotation of the bricks of this layer has been observed during the tests. We can also see that for the case of sliding (Figure $10 \mathrm{p}$ ), the piece of wood that fixed the first row of bricks coerced the failure to occur between the first and the second layer of bricks. Herein, overturning occurred for more slender walls and sliding for the less slender ones (Figure 11,.

\section{Validation of an analytical method of design}

\subsection{Analytical method based on the Coulomb's wedge theory}

The pseudo-static method (plain strain condition) is a simplified method recommended by the Eurocode 8 to address the seismic behaviour of retaining walls where analytical calculations can be performed. In particular, the Coulomb's 


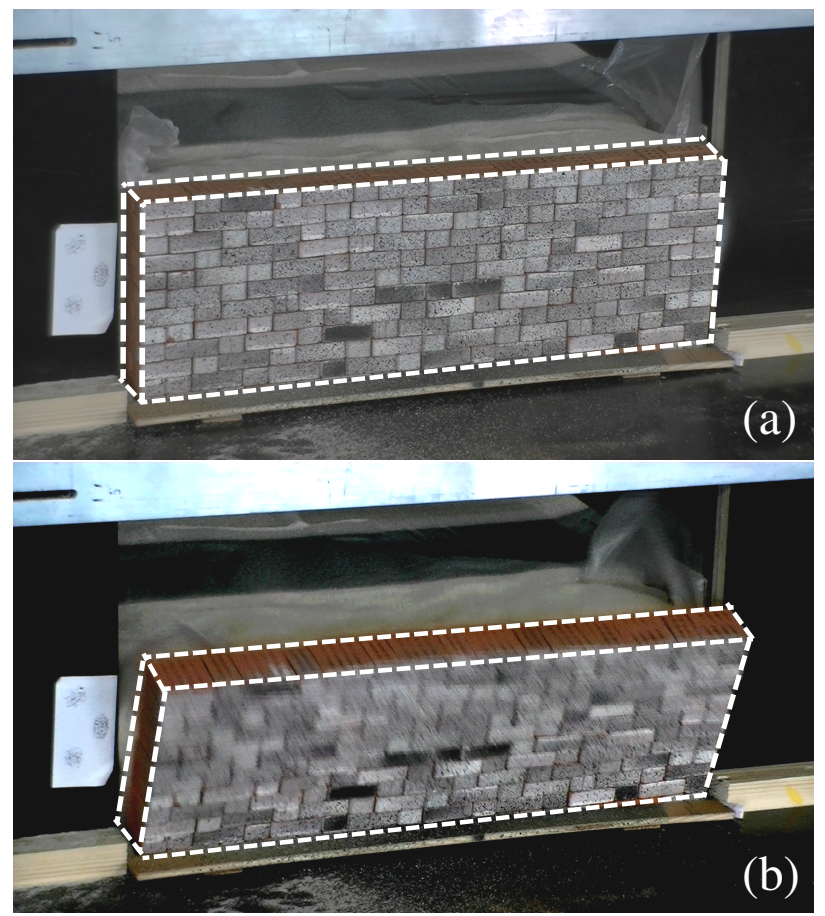

Figure 8: Failure by overturning. (a) Before failure. (b) After failure.

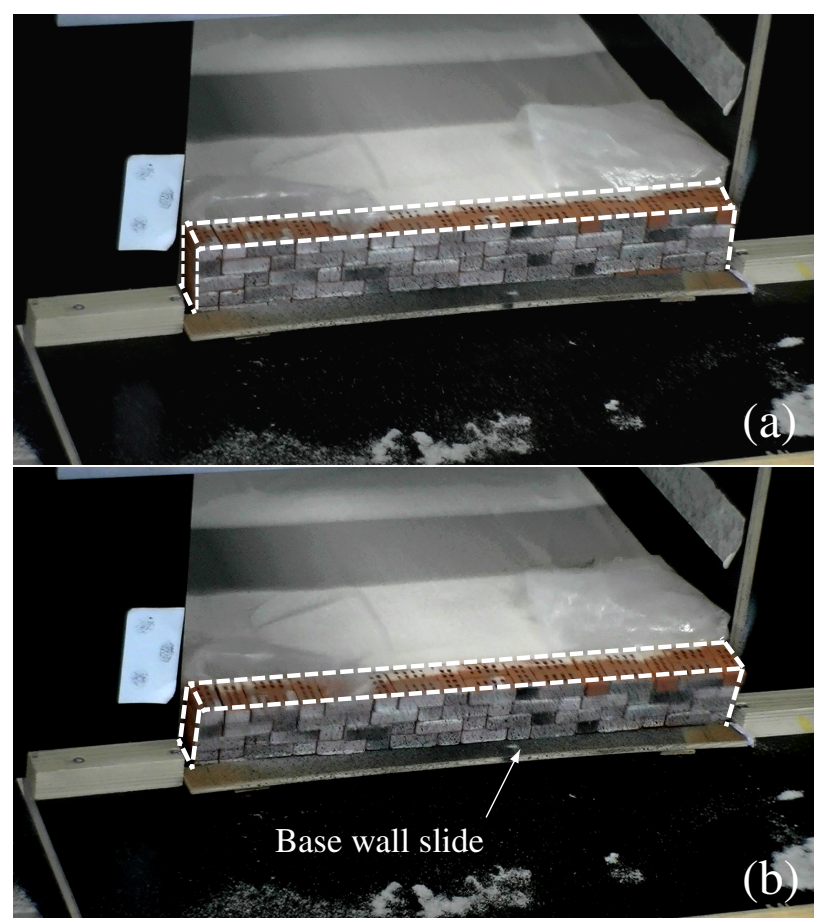

Figure 9: Failure by sliding. (a) Before failure. (b) After failure. The second row of bricks is sliding on the first row.

wedge theory which is a typical method (limit equilibrium) in soil mechanics is used herein. After a validation of this method in the case of DSRWs, a seismic design of DSRWs is proposed.

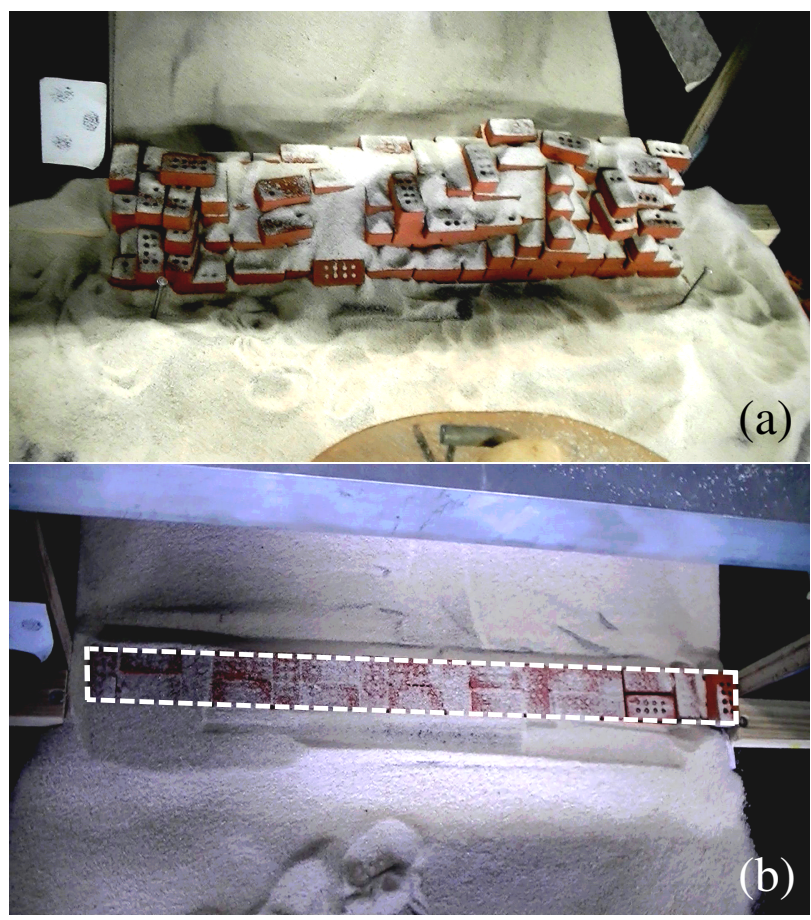

Figure 10: Part of the wall that remained intact during the tilting test. (a) Overturning (width $B=85 \mathrm{~mm}$ ) (b) Sliding (width $B=34 \mathrm{~mm}$ ).

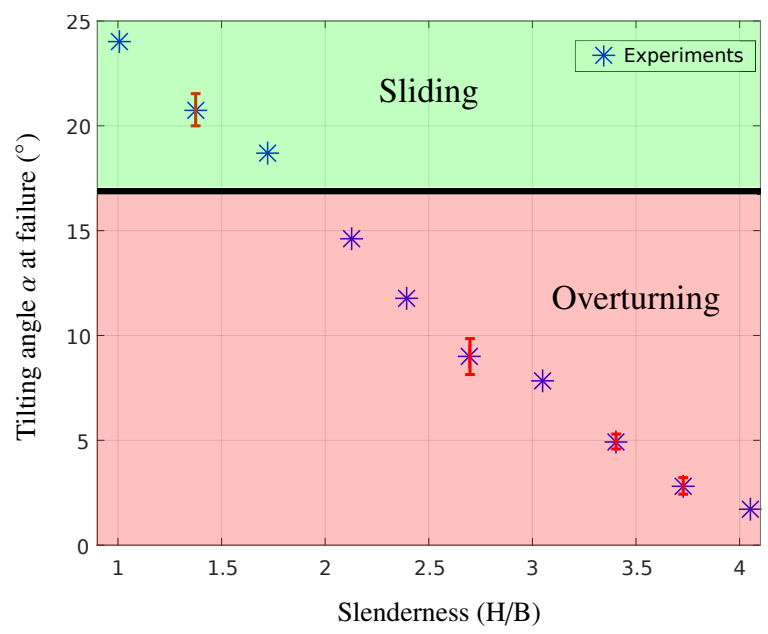

Figure 11: Two observed different modes of failure: overturning and sliding.

In the Coulomb's wedge theory, a wedge of soil applies a force due to earth pressure on the wall which can be computed considering the equilibrium of the soil wedge. The soil wedge is supposed to be rigid and at failure. This failure curve, separating the wedge at failure from the intact part of the backfill, is supposed to be a straight line in a plain strain problem, oriented by a angle $\theta$ with the horizontal (Figure 12). It must be noted that for DSRWs, the failure line can cross the wall which is a feature of these structures. This line is oriented by the angle $\omega$ with the horizontal passing at the top of the first row of bricks. We remind that the translational movement of 
this first row of bricks was blocked by a piece of wood in the scaled-down experiments.

The angle $\theta$ is obtained by solving the equilibrium of the soil wedge and provides a maximum value for the earth pressure resultant force $F_{e}$. Then, the angle $\omega$ is obtained by solving the equilibrium of the wall. The most critical situation for the wall determines the value of $\omega$.
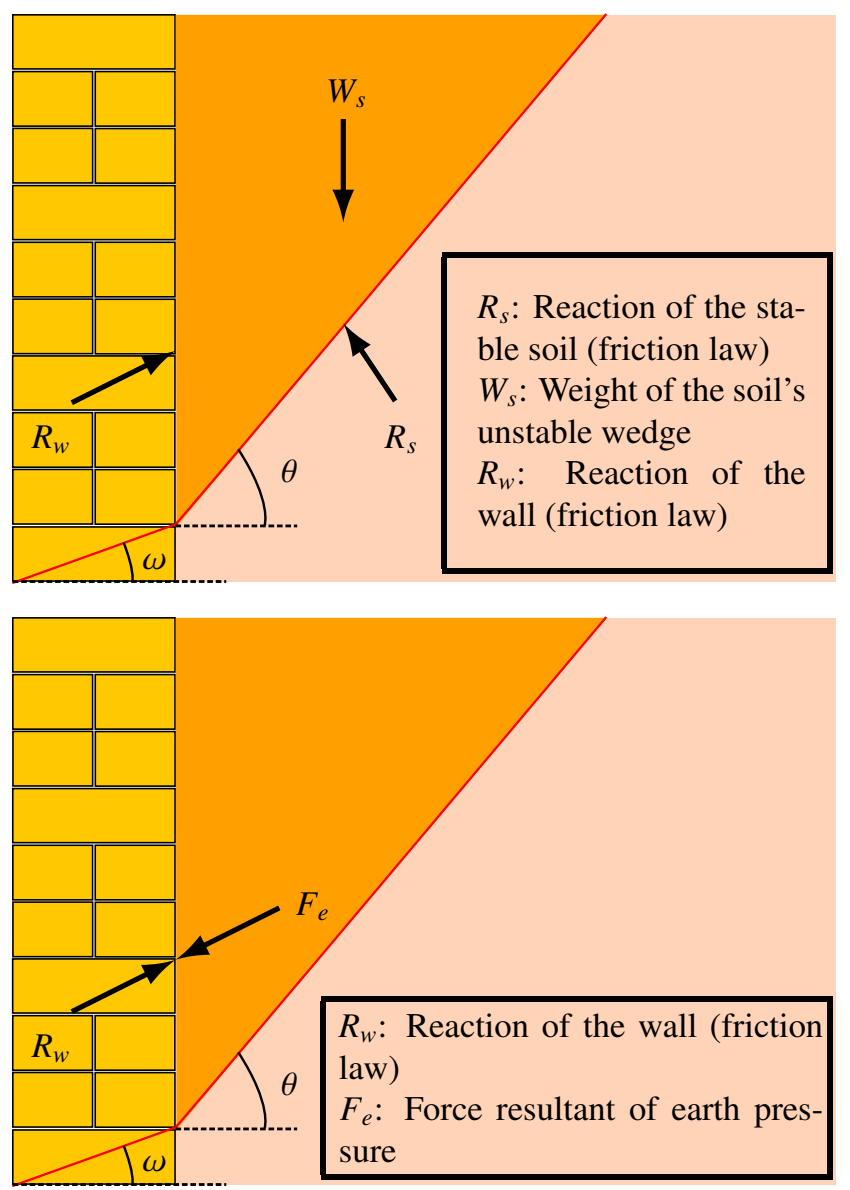

Figure 12: Static limit equilibrium for the Coulomb's wedge of soil. The earth pressure is acting at one-third height of the retaining wall (from bottom wall).

Extra inertial forces $F_{s}$ and $F_{w}$ due respectively to the displaced soil wedge during the seismic motion and to the proper wall displacement are added to the static forces (Figure 13. They are defined as:

$$
F_{w}=M_{w} * a_{h}
$$

with $a_{h}$ the representative value of the horizontal acceleration of the seismic motion and $M_{w}$, the mass of the wall. This force is acting at the center of gravity of the wall.

$$
F_{s}=M_{s} * a_{h}
$$

with $M_{s}$ representing the mass of the soil wedge. This force is acting at the center of gravity of the Coulomb's wedge. The

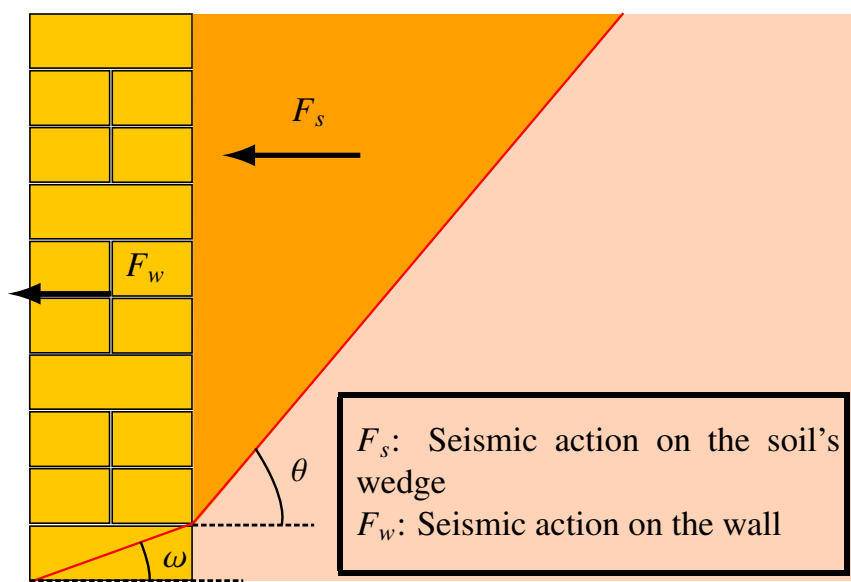

Figure 13: Pseudo-static forces modelling the seismic actions on the soil and on the wall.

force related to the earth pressure is deduced from the new equilibrium.

In the following, the two typical modes of failure (overturning and sliding) are considered for the analytical simulation (Figure 14).

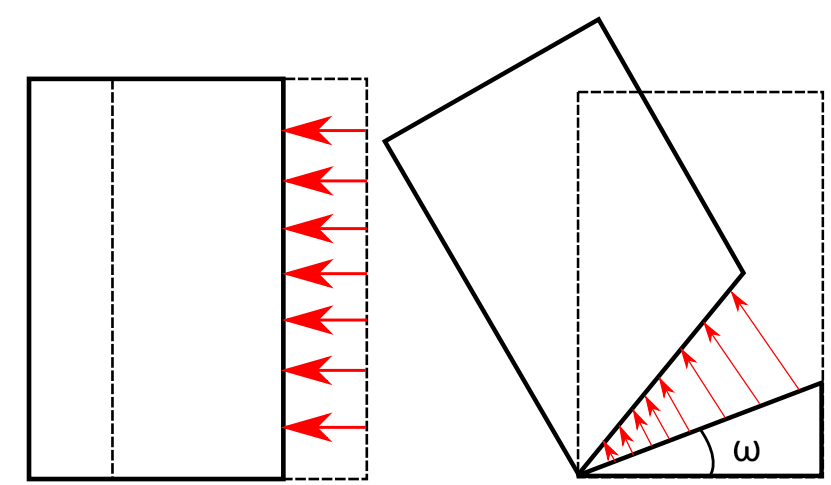

Sliding

Overturning

Figure 14: Two modes of failure. The value of $\omega$ depends on the geometry of the blocks and on their assemblage.

As the mock-up is inclined, the natural gravity is decomposed into two components: $a_{h}$ which is the pseudo-static action directly related to $F_{s}$ and $F_{w}$ and $a_{v}$ which represents the component of gravity parallel to the inward wall face (Figure 15). At each increment of the angle of inclination, the analytical model checked if the backfill-wall system was stable considering the two possible modes of failure (Figure 14). When the system was not anymore stable against one of these failure modes, the method stopped and returned the tilting angle as a result. 


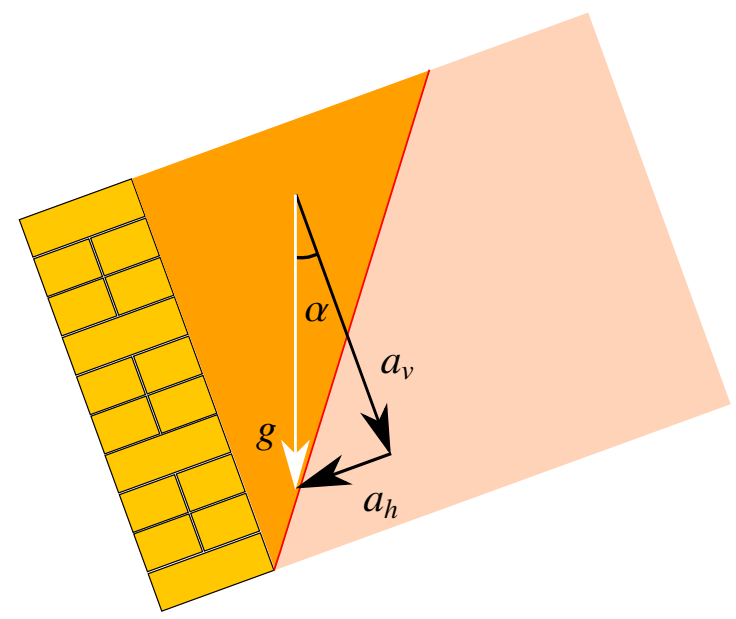

Figure 15: The inclination of the mock-up corresponds to an inclination of the gravity. The gravity is decomposed in two components.

\subsection{Validation of the method}

A validation of the Coulomb's wedge theory is proposed on the basis of the scaled-down experiments (Section 3). The physical and mechanical parameters of the backfill-wall system are given in Table 1 .

Table 1: Physical and mechanical parameters related to the backfill-wall system.

\begin{tabular}{l|cccc} 
Properties & Blocks & Wall & Fill & Interface \\
\hline \hline Physical properties & & & & \\
\hline Density $\left(\mathrm{kg} \cdot \mathrm{m}^{-3}\right)$ & 1640 & 1470 & 1304 & - \\
Unit weight $\left(\mathrm{N} \cdot \mathrm{m}^{-3}\right)$ & 16040 & 14420 & 13150 & - \\
\hline Mechanical properties & & & & \\
\hline$\phi\left(^{\circ}\right)$ & 32 & - & 32 & 22.7 \\
Cohesion $(\mathrm{kPa})$ & 0 & - & 0 & 0 \\
\hline
\end{tabular}

The results of the analytical method are presented in Figure 16. The tilting angle found by the analytical method fairly matches the results obtained in the experiments. Thanks to the video-shooting of the tests, the angle $\omega$ obtained through the optimisation process inherent to the Coulomb's wedge theory was compared to those found in the experiments. In the case of sliding, both experiments and the analytical method gave a value for $\omega$ equal to $0^{\circ}$. However, in the case of overturning, the average experimental angle $\omega$ was found equal approximately to $10^{\circ}$ and constant for all slendernesses whereas the one found by the analytical method was systematically found larger than $40^{\circ}$. This difference incited us to study the influence of this angle $\omega$ on the results in more detail.

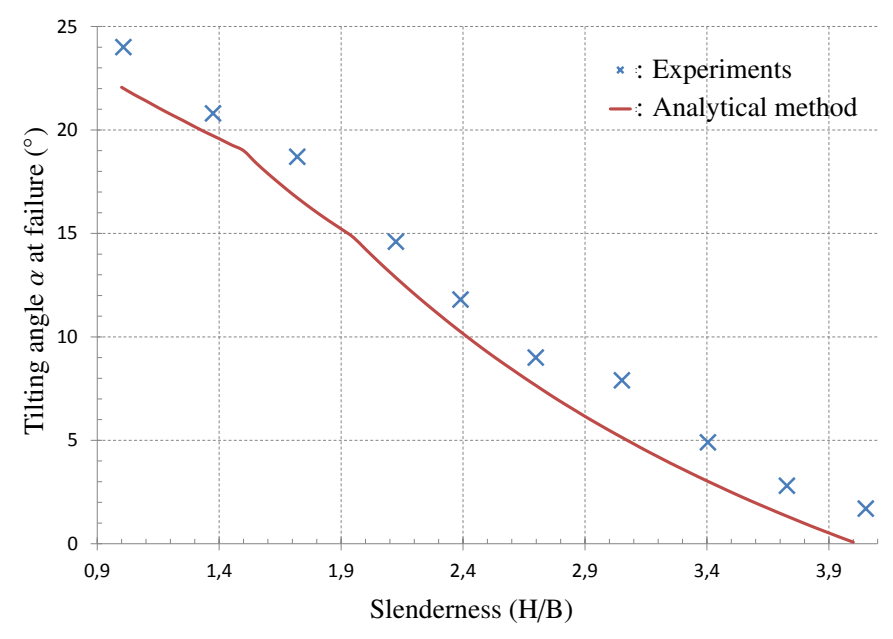

Figure 16: Validation of the analytical method.

\subsection{Improvement of the analytical method}

Since the final value for $\omega$ in the analytical method arises from the calculation of the most critical case for the stability of the wall, it does not necessarily correspond to what occurs in actual tests. Three different cases are explored where the calculation of $\omega$ was restrained to a maximum value $\omega_{\max }$ (Figure 17), which is equivalent to impose the angle of the failure line through the wall with the horizontal in the overturning mode of failure. Indeed, the higher $\omega$, the more critical the configuration is (Figure 17). As expected, the analytical results are greatly influenced by this stated maximum value for $\omega$. The case where $\omega$ is not limited gives the smaller tilting angle at failure. Any limitation for $\omega$ tends to increase this value and thus the resistance of the wall.

The concern relating to identify or to impose the angle $\omega$ in the calculation of DSRWs stability has already been accounted by other authors. Le [11] and Alejano [23] have pointed out that this angle depends on the geometry of the blocks. Villemus [3], Colas [24] and Le [11] noted that it also depends on the ability of stones to rotate within the wall which is the case in actual DSRWs where blocks have an irregular shape leading to a high porosity. This is not the case in this work were the geometry of blocks and the optimised arrangement cannot induce such a high porosity. Actually, this ability of stones to rotate decreases the resistance against sliding of these walls.

In fact, the geometry of the wall and of the blocks impose a bound on the angle $\omega$ (Figure 18). Indeed, the failure line can not go through blocks and is coerced to develop in the joints (Figure 10a): thus the smaller the blocks are, the steeper the failure line is. Figure 18 shows two cases assuming that the failure line intersect the top-left corner of the first row of bricks. In Figure 18, the small block size allows the development of a steep failure line. In Figure $18 \mathrm{p}$, this latter failure line (dashed line) can not develop due to larger block size and is bound to cross the wall according to a flatter angle. This case is more 


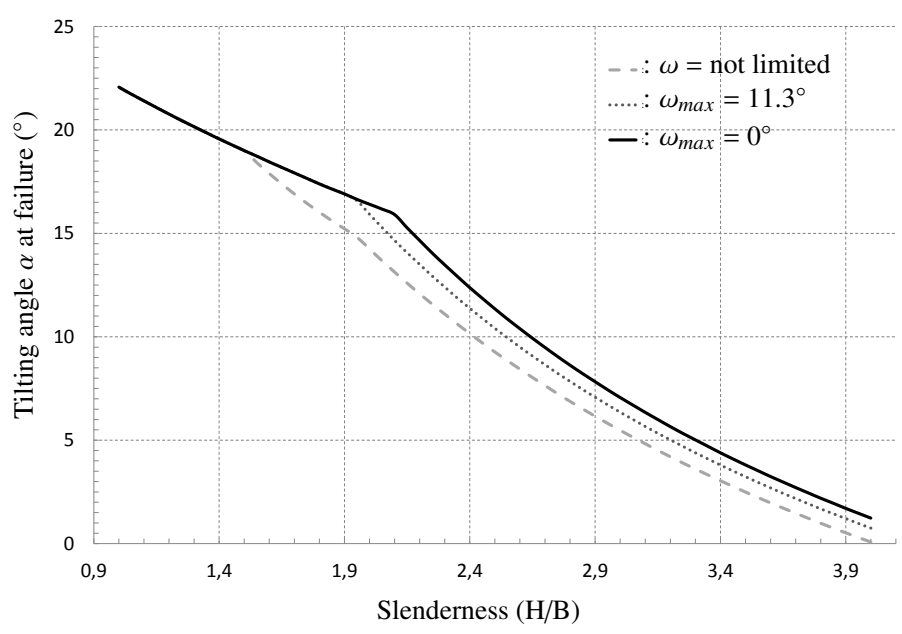

Figure 17: Three simulations with different conditions for $\omega$; non limited or limited to a maximum value $\omega_{\max }$.

favorable for the stability of the wall.

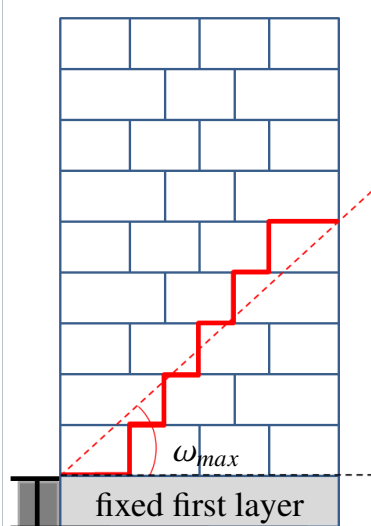

(a)

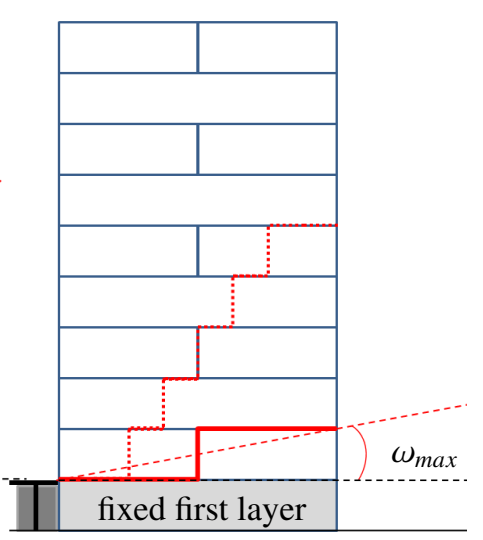

(b)
Figure 18: Restrictions for the value of $\omega$. (a) few restriction; (b) strong restriction.

Moreover, it must be noted that the more the headers in the wall are, the smaller the angle $\omega$ can be. Headers increase the mechanical stability of DSRWs in addition to insuring the global bond strength of walls. Thus, the tilting angles at failure $\omega$ within the experiments were studied in the light of the considered assemblages of the wall bricks in more detail even if it is not an easy task to accurately measure this value.

The width of experimental walls used in Figure 16 were all equal to $34 \mathrm{~mm}$ and the arrangement did not change between tests. Figure $19 \mathrm{a}$ gives the typical arrangement used with headers (cross-section 1) and stretchers (cross-section 2) for the second layer of bricks. In the experiments, the existing pattern with headers and stretchers did not allow the standing of an angle of failure $\omega$ larger than $0^{\circ}$ in cross-section 1 while in cross-section 2 the front block tilted and the rear block remained at its place (Figure 19 and Figure 20). In this latter cross-section, one can notice that the geometry of the blocks that remained at its place completely defined the value of $\omega$ (Figure 19.). Consequently, in order to improve the result of the analytical method, we propose to limit the valid values for the angle $\omega$ in the analytical method considering the type of arrangement and the geometry of the blocks.

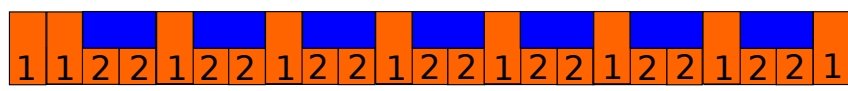

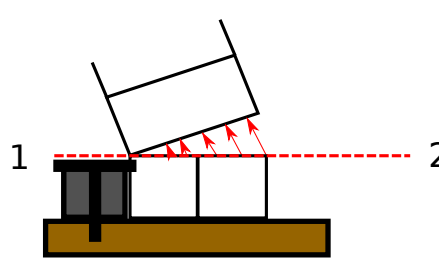

$\omega_{1 \max }=0^{\circ}$

(b)

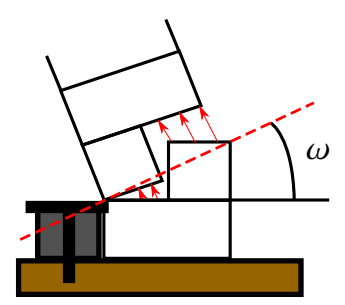

$\omega_{2 \max }=18.4^{\circ}$

(c)
Figure 19: Failure surface depends on the existence of header and stretcher in a given cross-section. (a): plan view of second layer of bricks with headers and stretchers and the type of cross-section, 1 or 2. Light color: bricks falling. Dark color: bricks remaining stable; (b): case of cross-section 1, (c): case of cross section 2 .

A smaller boundary value $\omega_{\min }$ is set to zero (equal to the inclination of the wall's bed of the brick layers), while the upper boundary value $\omega_{\max }$ is calculated as a weighted contribution of the two possible cross-sections (1 or 2) presented here before (denoted respectively $\omega_{1 \max }$ and $\omega_{2 \max }$ ). $\omega_{1 \max }$ is equal to $0^{\circ}$ and in the case of the geometry of the blocks used herein, $\omega_{2 \max }$ is equal to $18.4^{\circ}$ (Figure 19 ). Indeed in this case, $\omega_{2 \max }$ is merely associated to the ratio between the height and the length of the blocks. Then, $\omega_{\max }$ is computed as:

$$
\omega_{\max }=\omega_{1 \max } * r_{h}+\omega_{2 \max } * r_{s}=0 * \frac{9}{23}+18.4 * \frac{14}{23}=11.3^{\circ}
$$

where $r_{h}$ and $r_{s}$ are respectively the ratio of full headers and stretchers in the length of the investigated wall. In addition, the pattern observed in the cross sections 1 (Figure 19p) showed that the headers of the second row of bricks rotated during the failure but came back to their initial position (Figure 20]. Figure 21 illustrates this point with the rotation of the header belonging to the second row. It implies that the pattern of a wall after an overturning failure does not generally give the value of the failure angle $\omega$ in the wall. Nevertheless it gives an order of magnitude of its value.

Figure 22 gives the results for the analytical method while imposing the range of values for $\omega$ of $\left[0 ; \omega_{\max }=11.3^{\circ}\right]$. The prediction is in a very good agreement with the results 


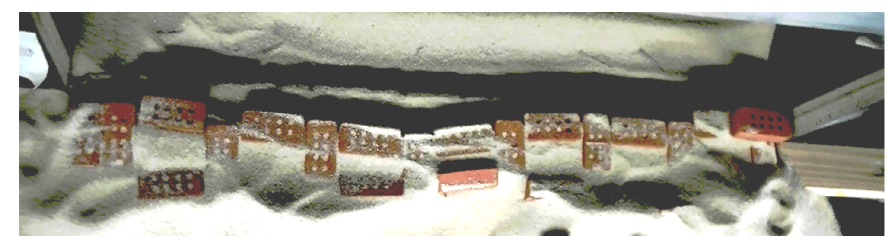

Figure 20: Pattern after a failure of a wall of thickness $34 \mathrm{~mm}$.

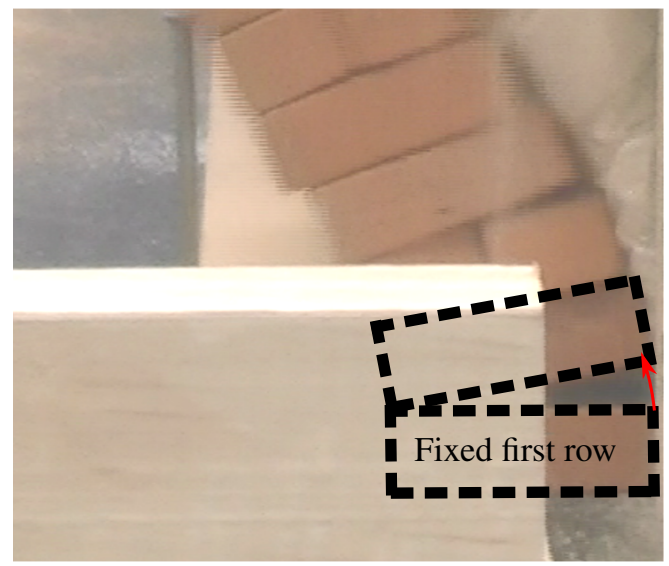

Figure 21: Rotation of the header of the second row of bricks at failure before coming back to its initial position.

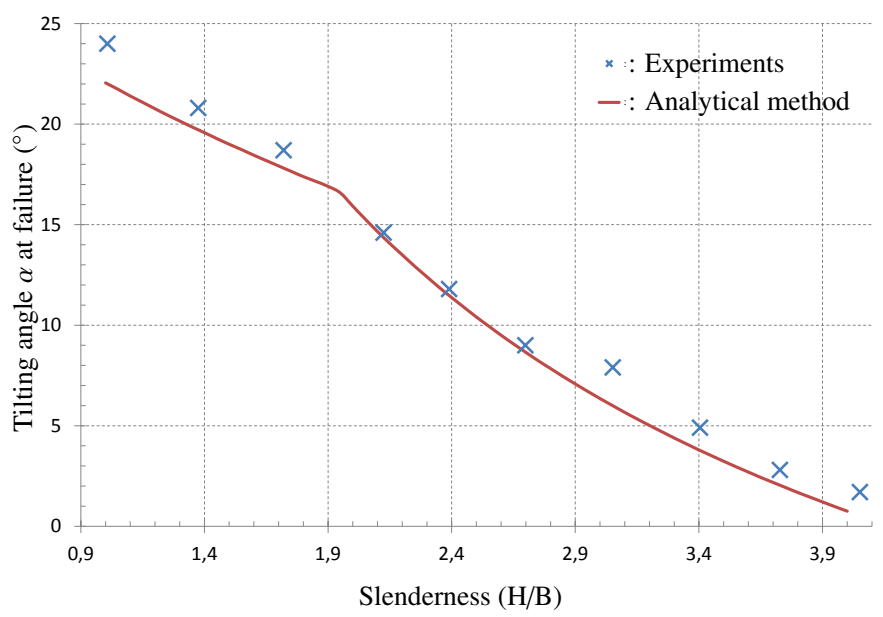

Figure 22: Validation of the improved analytical method.

observed through the experiments. Moreover, the two modes of failure were correctly predicted. Indeed, in the analytical method the transition slenderness between a sliding mode of failure to an overturning mode of failure was found for $\mathrm{H} / \mathrm{B}=$ 1.9 while this was observed for $\mathrm{H} / \mathrm{B}$ between 1.8 and 2.0 in the experiments.

However, in other cases where the investigated base wall widths were equal to $51 \mathrm{~mm}, 68 \mathrm{~mm}$ or $85 \mathrm{~mm}$, it was observed that the tilting angle at failure varied from $11^{\circ}$ to $22^{\circ}$. It highlights that Eq. 3 cannot be used in a general case and depends on the arrangement of blocks.

\subsection{Conservative estimate of the failure angle of the wall $\omega$}

In experiments on actual DSRWs, the recommandations to assess the value of the failure angle $\omega$ are based on experimental observations [3] or drawn from geometrical [25] or empirical [11] observations but not based on the geometry of blocks. Considering the experiments presented herein, there may be a limitation to the quality of the results provided by an analytical method.

Following the researchers who proposed to determine this value considering the arrangement of blocks on the outward face of the wall [23], a conservative estimate of $\omega_{\max }$ for improving the results provided by the Coulomb's wedge theory is proposed. This estimate, denoted $\omega_{c \max }$, is determined on geometrical considerations and on the basis of Eq. 3 Simplifying Eq. 3, one gets:

$$
\omega_{c \max }=r_{s} * \omega_{2 \max }=r_{s} * \operatorname{atan}\left(\frac{\mathrm{h}}{\mathrm{e}}\right)
$$

where $r_{s}$ is the ratio of stretchers in the length of the investigated wall. $e$ corresponds to the mean horizontal size of blocks $(L+$ l) $/ 2$. For actual DSRWs, the ratio $r_{s}$ can be deduced from the ratio of full headers: $r_{s}=1-r_{h}$. This ratio $r_{h}$ can be known in the case of new DSRWs but has to be assessed for existant walls. Default and conservative values are $r_{h}=0$ and $r_{s}=1$. Using Eq. 4 for the scaled-down experiments, since there is no full headers (block that entirely crosses the wall) in the walls of width $\mathrm{B}=51 \mathrm{~mm}, 68 \mathrm{~mm}$ or $85 \mathrm{~mm}$, we assume that $r_{h}=0$ which implies that the ratio of stretchers $r_{s}$ in the length of the wall is equal to 1 . Considering the blocks geometry $\left(\mathrm{L}^{*} \mathrm{l}^{*} \mathrm{~h}\right.$ $=34 * 17 * 11.3 \mathrm{~mm}$ ) used in this work, a conservative estimate value for the maximum tilting angle $\omega_{c \max }$ is equal to:

$$
\omega_{c \max }=1 * \operatorname{atan}\left(\frac{11.3}{25.5}\right)=24^{\circ}
$$

For the special case where the base wall width was $34 \mathrm{~mm}$ allowing to the presence of some full headers : $r_{s}=14 / 23=$ 0.6 and in this case the estimate for $\omega_{c \max }$ reads:

$$
\omega_{c \max }=0.6 * \operatorname{atan}\left(\frac{11.3}{25.5}\right)=14.5^{\circ}
$$

This estimate is fairly close to the value derived from Eq. 3 which was equal to $11.3^{\circ}$.

As a validation for actual DSRWs, Eq. 4 was used in the case of the full-scale tests carried out by Villemus [26]. He used schist stone of mean size in a cross section equal to $10 \mathrm{~cm}^{*} 30 \mathrm{~cm}^{1}$ without using any full header. The walls were built following the recommendations of the practitioners [27]. During the experiments, he observed an average value for the tilting angle at failure $\omega$ of $10^{\circ}$. In this case, like in most

\footnotetext{
${ }^{1}$ This value have been computed by averaging the dimensions of 20 blocks
} 
of actual cases, there was no full header crossing the wall thickness which means that we can state: $r_{h}=0$ and $r_{s}=1$. Then, using Eq. 4. $\omega_{c \max }$ is estimated at $18^{\circ}$ which is higher but close to the actual value. Therefore, the proposed simplified approach (Eq. 4) is conservative.

To conclude, we proposed herein a technique to estimate the maximum tilting angle at failure $\omega$ based on geometrical considerations related to the size of the average block used to build the retaining wall. This technique allows the Coulomb's wedge theory to provide results closer to experiments but on the conservative side for the design of the wall. In the case the mason does not know the ratio of full headers, default (and conservative) value $r_{s}=1$ can be taken. In very special cases, where the assemblage of the DSRW is perfectly known, the study of the failure line within the wall is possible and a better estimate of the tilting angle $\omega$ can be drawn following the scheme developped in Section 4.3 leading to Eq. 3 .

\section{Preliminary implications for the seismic design of DSRWs}

This section aims at comparing the static design of specific DSRWs to their pseudo-static design using the improved analytical method presented in this paper. This comparison will lead to some preliminary implications for the seismic design of actual DSRWs where some critical cases will be studied. For a given soil, a given wall material and a typical height of the wall, both the base width for a static design and for a seismic design of the wall are provided by the improved analytical method. The extra base width required for the pseudo-static design is then extracted.

\subsection{Application of the improved analytical method to actual DSRWs}

\subsubsection{Accuracy of the method for DSRWs}

DSRWs are different from the scaled-down walls studied in this paper where the geometry, arrangement and dispersion of properties can be far greater than those measured in the experiments carried out in this work.

In fact, even if actual DSRWs are built with rubble stones whose shape is different from the parallelepipedic clay bricks involved in this work, past numerical simulations involving idealised block geometries in the case of DSRWs proved sufficient to retrieve quantitative phenomena observed in actual DSRWs [7]. Moreover, the homogenous model of Colas [4, 28] that involves idealised blocks has been able to predict the failure of actual DSRWs with a good accuracy. It implies that contrary to the block dimensions, the imperfections of the geometry of stone blocks (compared to parallelepipedic bricks) do not play a significant role in the stability of DSRWs. At this stage, we must remind that in the analytical or numerical computations, the unit weight of walls is smaller than the unit weight of the blocks in actual walls and take into account the porosity existing between blocks.

Since the size of the DSRWs and the size of the scaled-down walls are different, some scale effects could exist and alter any generalisation from scaled-down experiments. However, it has been shown that limit-equilibrium methods (as the one developped here) were accurate enough to retrieve the behaviour of full-scale experiments in static configurations [3, 5, 29].

\subsubsection{Parameters of the studied wall}

As mentioned before, only few cases are investigated in this section to give some trends for the seismic design of DSRWs using a pseudo-static approach. Indeed, since there exists a variety of both geometrical and mechanical configurations along with different site conditions, it seems difficult to be exhaustive. However, the simplicity of the method allows fast computations and makes it easy to adapt to specific cases. In order to see the influence of the material constituting the blocks and the possible variability of derived implications, three typical but different materials for the blocks are considered in the following. Then, three cases will be studied: one wall made of schist stones, another one made of limestone and a last one made of calcareous molasse. The properties of walls are summed up in Table 2 .

The geometrical properties $(\mathrm{h}, \lambda, \beta)$ of the wall as well as the properties of the backfill $\left(\gamma_{\text {fill }}, \Phi_{\text {fill }}, C_{\text {fill }}, \delta_{\text {interface }}\right)$ are drawn from the French professional standards for a static design of DSRWs [30]. Note that in this cases, no cohesion for the backfill is taken into account. The friction of the interface between the backfill and the wall is taken equal to the friction of the backfill considering the roughness of the back face of actual DSRWs as it is commonly done in DSRWs studies. The geometry of the wall is chosen to be the simplest as possible (no batter, no inclination of the bed) and the height of $2.5 \mathrm{~m}$ is considered to be a typical height for DSRWs [28]. The unit weight and the friction between blocks are drawn from the French professional standards for static design of DSRWs [30]. The value of $\omega_{c \max }$ is derived from full-scale experiments on actual DSRWs [3, 24, 28] using Eq. 4 Since the typical sizes of actual blocks depend on the nature of the material constituting the blocks (schist, limestone, among others), Eq. 4 will provide different values for $\omega_{c \mathrm{max}} \sqrt{2}$ for processing the improved analytical method.

\subsection{Computation of the seismic design acceleration}

Depending on the construction site of the DSRW, the Eurocode 8 [13, 31] gives the procedure to obtain the seismic design acceleration that the structure must withstand. It leads to Eq. 7

$$
a_{g}=a_{g r} * \gamma_{1} * S_{T} * S=\alpha S
$$

\footnotetext{
${ }^{2}$ The value $\omega_{c \max }$ for limestone and calcareous molasse has been drawn from the same full-scale tests [3, 28].
} 


\begin{tabular}{|c|c|c|c|c|}
\hline \multicolumn{5}{|c|}{ Main geometry and properties for the walls } \\
\hline Parameter & Meaning & \multicolumn{3}{|c|}{ Value } \\
\hline $\mathrm{h}$ & Height of the wall (m) & \multicolumn{3}{|c|}{2.5} \\
\hline$\lambda$ & External batter of the wall $(\%)$ & \multicolumn{3}{|c|}{0} \\
\hline$\beta$ & Inclination of the backfill's surface $\left(^{\circ}\right)$ & \multicolumn{3}{|c|}{0} \\
\hline$\gamma_{\text {fill }}$ & Unit weight of the backfill $\left(\mathrm{kN} \cdot \mathrm{m}^{-3}\right)$ & \multicolumn{3}{|c|}{20} \\
\hline$\Phi_{\text {fill }}$ & Backfill internal friction angle $\left(^{\circ}\right)$ & \multicolumn{3}{|c|}{28} \\
\hline$C_{\text {fill }}$ & Cohesion of the backfill $(\mathrm{kPa})$ & \multicolumn{3}{|c|}{0} \\
\hline$\delta_{\text {interface }}$ & Backfill-wall interface friction angle $\left(^{\circ}\right)$ & \multicolumn{3}{|c|}{28} \\
\hline \multicolumn{5}{|c|}{ Different materials for the blocks of the walls } \\
\hline Parameter & Meaning & Schist & Limestone & Molasse \\
\hline$\gamma_{\text {wall }}$ & Unit weight of the wall $\left(\mathrm{kN} \cdot \mathrm{m}^{-3}\right)$ & 15 & 15 & 12 \\
\hline$\Phi_{\text {wall }}$ & Block-block friction angle $\left(^{\circ}\right)$ & 27 & 36 & 36 \\
\hline$\omega_{c \max }$ & Estimate of the angle of the failure line crossing the wall ${ }^{3}\left({ }^{\circ}\right)$ & 18 & 20 & 20 \\
\hline
\end{tabular}

${ }^{3}$ Depends on the arrangement of the blocks; default value can be drawn from Eq. 4 and geometry of blocks from full-scale experiments [3] 24] 28]

where $a_{g}$ (fraction of $\mathrm{g}$ ) denotes the design acceleration (on the $\mathrm{X}$-axis in Figure 23, $a_{g r}$ (fraction of $\mathrm{g}$ ) denotes the reference acceleration on site (Table I and Figure I), $\gamma_{1}$ is linked to the importance of the human infrastructures around the wall (Table III), $S$ depends on the geotechnical conditions (Table III) and $S_{T}$ varies according to the topography of the site (Table IV]. Then, the final value for the design acceleration is equal to:

$$
a_{g, \text { reduced }}=\frac{a_{g}}{r}=\frac{\alpha S}{r}
$$

where, $r \in[1 ; 2]$ and characterizes the capacity of the wall to authorize either rigid body displacements or displacements related to the deformability of the structure (Table $\mathrm{V}$ ). In such cases, part of the seismic motion is absorbed to generate those displacements and is not transformed in seismic stresses in the structure. For example, an anchored wall is not able to move and, in this case, $r=1$.

To identify the value of $r$ in the case of DSRWs, two cases are distinguished depending on the failure mechanism. If the wall is about to fail in sliding (high acceleration or low slenderness), the wall can bear a displacement. Indeed, in the sliding mode, the entire wall moves on the underground blocks acting as foundation layer. Since for actual DSRWs the foundation is recommended to be larger than the base of the wall, it remains stable. This assumption is consolidated by experimental results from Villemus [3] where in the sliding mode of failure, the wall can move as a whole before failure appears. The maximum value of authorised displacement is drawn from these experiments and is equal to $100 \mathrm{~mm}$ for a wall of similar height. In this case, $r$ is taken equal to 1.5 according to the Eurocode 8. If the wall is about to fail in overturning (low acceleration or high slenderness), there is no authorised displacement. Indeed, the overturning mode of failure is characterised by a dislocation of the wall into a moving and a non moving part. Moreover, few displacements are typically observed before failure. For this mode of failure, $r$ is taken equal to 1 . These two values have been chosen to stay on the conservative side of the design.

\subsection{Comparison between static design and pseudo-static de- sign of three DSRWs}

For the three cases related to the different kind of wall materials, the base widths identified by the static design (drawn from French professional standards [30]) are respectively equal to $0.90 \mathrm{~m}, 0.88 \mathrm{~m}$ and $0.97 \mathrm{~m}$ for the walls with the schist, limestone and molasse stones.

Then, the pseudo-static design is processed using the improved analytical method. For a given design acceleration the mode of failure is identified and the corresponding reduced design acceleration is processed to find the base width compatible with the seismic design. Figure 23 gives the result as the extra-base width due to the seismic design compared to a purely static design for a given design acceleration $a_{g}$.

We can observe that below a design acceleration of approximately $0.08 \mathrm{~g}$, there is no need of an extra width for the wall to withstand the seismic motion. It is mainly due to the safety coefficients involved in the static design (respectively 1.2 and 1.5 for sliding and overturning compared to 1 in the seismic design for both modes of failure). For accelerations greater than $0.08 \mathrm{~g}$, the seismic design is more critical than the static design and the required base wall dimension increases with the seismic acceleration. In addition, this threshold is almost independent of the kind of material involved for the wall structure. However, this threshold may vary depending on the properties of the wall-soil system if different from the one given in Table 2 
Figure 23 shows that the case of the schist is different from the two other ones. Indeed, in this case, the extra base width required by the pseudo-static design does not evolve linearly with the design acceleration. This is due to the lower resistance against sliding (correlated with the friction of blocks) of the schist stones. However, the unit weight of the wall does not seem to greatly influence the extra base width required by the pseudo-static design as the curves for the limestone and the molasse curves are very close ${ }^{4}$

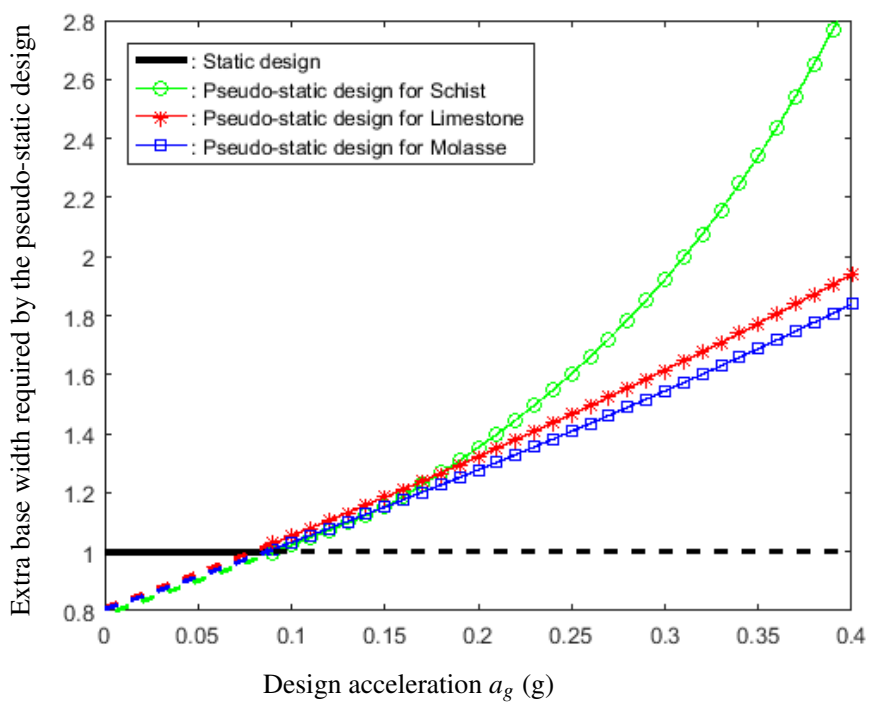

Figure 23: Static and pseudo-static design of a $2.5 \mathrm{~m}$ high wall depending on the involved material.

To give more insight into the seismic design of DSRWs using a pseudo-static approach and for brevity, particular cases including four different sites are presented in detail. First, a pessimistic but representative situation for mainland France is envisioned (Case S4): the DSRW is built in a medium seismic area (zone 4 in Table I) and close to a non-essential highway for the regional economy (class of Importance II in Table II). A class E soil condition is considered in this case, which is the most critical situation and which can occur in flat lands but also in some hilly areas. The slope is chosen lower than $30^{\circ}$, since slopes higher than $30^{\circ}$ correspond mainly to high mountains, where the other parameters are not so critical. The data of the configuration site S4 is presented in Table 3 . For this case, the extra base width required to withstand the seismic motion for the three kinds of wall material is given in Table 4

For calcareous molasse and limestone walls, the extra base width is about $80 \%$ whereas it soars to $160 \%$ in the case of the schist wall. These high (and somehow unrealistic) values of extra base width highlight the limits of the pseudo-static approach to correctly assess the seismic behaviour of DSRWs

\footnotetext{
${ }^{4}$ This last comment is valid only for the range of the studied design acceler${ }^{4}$ This
}

Table 3: Study of the worst configuration for the seismic design in mainland France. This configuration is however representative of some actual DSRWs (Case S4).

\begin{tabular}{|l|cccc|c|}
\hline & $\begin{array}{c}\text { Seismic } \\
\text { zone } a_{g r}\end{array}$ & $\begin{array}{c}\text { Impor- } \\
\text { tance } \gamma_{1}\end{array}$ & $\begin{array}{c}\text { Soil } \\
\text { class } S\end{array}$ & $\begin{array}{c}\text { Topogra- } \\
\text { phy } S_{T}\end{array}$ & $\begin{array}{c}\text { Design } \\
\text { acc. } a_{g}(\mathrm{~g})\end{array}$ \\
\hline Class & 4 & II & E & $\begin{array}{c}{\left[15^{\circ} ; 30^{\circ}\right]} \\
\text { soil E }\end{array}$ & Eq. 7 \\
\hline Value & 0.16 & 1.0 & 1.6 & 1.44 & 0.38 \\
\hline
\end{tabular}

Table 4: Extra base widths required to withstand the seismic motion in a critical site for three different wall materials (Table 2).

\begin{tabular}{|c|ccc|}
\hline Case S4 & $\begin{array}{c}\text { Schist } \\
\text { wall }\end{array}$ & $\begin{array}{c}\text { Limestone } \\
\text { wall }\end{array}$ & Molasse \\
& wall \\
\hline Failure mode & Sliding & Overturning & Overturning \\
Extra base width $(\%)$ & $160 \%$ & $86 \%$ & $76 \%$ \\
\hline
\end{tabular}

in medium seismicity zones (case S4). Nevertheless, as case $\mathrm{S} 4$ is envisioned as the most critical situation, the extra base width is not expected to be higher than $85 \%$ (or $160 \%$ for schist stone) in mainland France. These values are expected to be different in other geometrical an geotechnical wall-soil configurations than the one studied herein.

Then, the influence of the seismic area is studied. Case $\mathrm{S} 1$, case S2 and case S3 correspond respectively to very low seismicity areas, low seismicity areas and moderate seismicity areas. All the data used for processing case S4 are also used herein expect the seismic design acceleration which is a characteristic of each seismic area. Table 5 summarizes the results for the three considered seismic zones together with case $\mathrm{S} 4$ that was here before presented.

Table 5: Influence of the seismic zone on the extra base width. Case S1: very low seismicity. Case S2: low seismicity. Case S3: moderate seismicity. Case S4: medium seismicity. Symbol $(\mathrm{O})$ means an overturning mode of failure and symbol (S) a sliding mode of failure.

\begin{tabular}{|c|ccc|}
\hline $\begin{array}{c}\text { Extra base } \\
\text { width (\%) }\end{array}$ & $\begin{array}{c}\text { Schist } \\
\text { wall }\end{array}$ & $\begin{array}{c}\text { Limestone } \\
\text { wall }\end{array}$ & $\begin{array}{c}\text { Molasse } \\
\text { wall }\end{array}$ \\
\hline Case S1 & $1 \%(0)$ & $4 \%(0)$ & $2 \%(0)$ \\
Case S2 & $21 \%(0)$ & $22 \%(0)$ & $19 \%(0)$ \\
Case S3 & $65 \%(S)$ & $45 \%(0)$ & $43 \%(0)$ \\
Case S4 & $160 \%(\mathrm{~S})$ & $86 \%(0)$ & $76 \%(0)$ \\
\hline
\end{tabular}

The required extra base width for the seismic design dramatically decreases as the seismicity of the studied site decreases. One should note that the failure mode involved in the design of the schist wall changes from overturning (for low acceleration and high slendernesses) to sliding (for high acceleration and low slendernesses). In addition, the difference between schist wall and the two other ones is lower as the seismicity decreases, especially for low and very low seismicity zones (cases S2 and $\mathrm{S} 1$ ) where the extra base width required for the three materials 
is similar for each seismicity zone.

Looking at the map of seismicity of mainland France, we can notice that very low seismicity zones correspond to approximately $40 \%$ of the mainland territory. It means that for $40 \%$ of mainland France, even with a pseudo-static approach the maximum extra width required to bear the seismic motion is low (4\%). Even for the low seismic risk zones (approximately $30 \%$ of mainland France), the maximum extra width required by a pseudo-static approach is of about $22 \%$ for the critical studied cases.

\section{Conclusion}

In this study, a pseudo-static analysis of the behaviour of DSRWs has been provided. First, scaled-down experiments have been carried out on a backfill-retaining wall system in order to study the influence of the geometry of the wall on its seismic resistance. Then, an analytical method based on the Coulomb wedge theory able to address the seismic design of DSRWs within the framework of a pseudo-static approach has been designed and validated on the basis of the scaled-down experiments.

The typical modes of failure found in actual full scale experiments on DSRWs were exhibited throughout the experiments carried out. The proposed basic analytical method proved enough accurate to predict the tilting angle of the mock-up leading the system to failure. An improvement of the method was proposed requiring the knowledge of the block geometry.

The proposed improved analytical method can be used to give preliminary implications for the seismic design of typical DSRWs in France. The patterns observed for walls with limestone or molasse are similar with a quasi linear evolution of the extra width with respect to the design acceleration due to failure is always of the overturning type. It is not the case for the schist case where sliding is predominant for even smaller design accelerations. In $70 \%$ of mainland France (considering lower seismic risk zones), the extra width required to withstand the seismic motion does not exceed $25 \%$ according to the developed method and is rather independent of the kind of material involved in the wall. However, it gives some unrealistic values of extra base width for areas where the seismicity is higher. Since the pseudo-static approach is known to be overconservative in this case, further dynamic studies of DSRWs will be required to provide a better estimate of the extra base width for a seismic design of DSRWs in zones of medium intensity.

\section{Acknowledgement}

This work is part of the French national project ANR126VBU-0001-06, aiming at studying the behaviour of rock and earth structures. The authors acknowledge the National Agency of Research (France, ANR) for its financial support.

\section{References}

[1] J. Burgoyne, Revetments of retaining walls, Corps of Royal Engineers Papers 3 (1853) 154-159.

[2] M. Cooper, Deflections and failure modes in dry-stone retaining walls, Ground Engineering 19 (1986) 40-45.

[3] B. Villemus, J.-C. Morel, C. Boutin, Experimental assessment of dry stone retaining wall stability on a rigid foundation, Engineering Structures 29 (2006) 2124-2132.

[4] A.-S. Colas, J.-C. Morel, D. Garnier, Yield design of dry-stone masonry retaining structures - comparisons with analytical, numerical, and experimental data, International Journal for Numerical and Analytical Methods in Geomechanics 32 (2008) 1817-1832.

[5] C. Mundell, P. McCombie, C. Bailey, A. Heath, P. Walker, Limitequilibrium assessment of drystone retaining structures, Proceedings of the Institution of Civil Engineers - Geotechnical Engineering 162 (2009) 203-212.

[6] X. Zhang, N. Koutsabeloulis, S. Hope, A. Pearce, A finite element analysis for the stability of drystone masonry retaining walls, Géotechnique 54 (2004) 57-60.

[7] J. J. Oetomo, E. Vincens, F. Dedecker, J. C. Morel, Modeling the 2D behavior of dry-stone retaining wall by a fully discrete element method, International Journal for Numerical and Analytical Methods in Geomechanics (2015).

[8] R. Harkness, W. Powrie, X. Zhang, K. Brady, M. O’Reilly, Numerical modelling of full-scale tests on drystone masonry retaining walls, Géotechnique 50 (2000) 165-179.

[9] W. Powrie, R. Harkness, X. Zhang, D. Bush, Deformation and failure modes of drystone retaining walls, Géotechnique 52 (2002) 435-446.

[10] M. Claxton, R. Hart, P. McCombie, P. Walker, Rigid block distinctelement modelling of dry-stone retaining walls in plane strain, ASCE Journal of Geotechnical and Geoenvironmental Engineering 131 (2005) 381-389.

[11] H. H. Le, J.-C. Morel, D. Garnier, P. F. McCombie, A review of methods for modelling drystone retaining walls, Proceedings of the Institution of Civil Engineers - Geotechnical Engineering (2014).

[12] J.-C. Quezada, E. Vincens, R. Mouterde, J.-C. Morel, 3d failure of a scaledown dry stone retaining wall : a dem modelling, Engineering Structures 117 (2016) 506-517.

[13] Association Française de Normalisation (AFNOR - French standard institute), NF EN 1998-5:2005 (eurocode 8) : Design of structures for earthquake resistance - part 5: Foundations, retaining structures and geotechnical aspects, 2005 .

[14] S. Okabe, General theory of earth pressure, Journal of the Japanese Society of Civil Engineers 12 (1926).

[15] N. Mononobe, H. Matsuo, On the determination of earth pressures during earthquakes, in: World Engineering Conference, volume 9, 1929, p. 176.

[16] H. B. Seed, R. V. Whitman, Design of earth retaining structures for dynamic loads, in: Special Conference on Lateral Stresses, Ground Displacement and Earth Retaining Structures, Ithaca, NY, USA, 1970, pp. 103-147.

[17] R. Richards, D. Elms, Seismic behavior of gravity retaining walls, Journal Of The Geotechnical Engineering Division 105 (1979) 449-464.

[18] H. S. M. H. Baziar, M. R. Moghadam, Sliding stability analysis of gravity retaining walls using the pseudo-dynamic method, Geotechnical Engineering 166 (2013) 389-398.

[19] I. Bellezza, A new pseudo-dynamic approach for seismic active soil thrust, Geotechnical and Geological Engineering 32 (2014) 561-576.

[20] D. Choudhury, A. D. Katdare, New method to compute seismic active earth pressure on retaining wall considering seismic waves, Geotechnical and Geological Engineering 32 (2014) 391-402.

[21] J. D. E. Flavigny, B. Palayer, Note technique-le sable d'hostun, Revue franaise de géotechnique (1990) 67-70.

[22] C. Mundell, P. McCombie, A. Heath, J. Harkness, Behaviour of drystone retaining structures, Proceedings of the Institution of Civil Engineers Structures and Buildings 163 (2010) 3-12. 
[23] L. Alejano, M. Veiga, J. Taboada, M. Dez-Farto, Stability of granite drystone masonry retaining walls: I. analytical design, Géotechnique 62 (2012) 10131025.

[24] A.-S. Colas, J.-C. Morel, D. Garnier, Full-scale field trials to assess drystone retaining wall stability, Engineering Structures 32 (2010) 12151222.

[25] A.-S. Colas, J.-C. Morel, D. Garnier, 2D modelling of a dry joint masonry wall retaining a pulverulent backfill, International Journal for Numerical and Analytical Methods in Geomechanics 34 (2010) 1237-1249.

[26] B. Villemus, Etude des Murs de Soutènement en Maonnerie de Pierre Sèches, Ph.D. thesis, Ecole Nationale des Travaux Publics de l'Etat (ENTPE), 2004

[27] C. de l'Artisanat et des Petites Entreprises du Bâtiment (CAPEB), A. B. en Pierres Sèches (ABPS), M. de Provence, C. des Bâtisseurs en Pierre Sèche (CBPS), C. de Métiers et de l'Artisanat de Vaucluse (CMA84), U. de Lyon Ecole Nationale des Travaux Publics de l'Etat (ENTPE), Pierres sèches : guide de bonnes pratiques de construction de murs de soutènement, CAPEB, 2008

[28] A.-S. Colas, J.-C. Morel, D. Garnier, Assessing the two-dimensional behaviour of drystone retaining walls by full-scale experiments and yield design simulation, Géotechnique 63 (2013) 107117.

[29] L. Alejano, M. Veiga, I. Gmez-Mrquez, J. Taboada, Stability of granite drystone masonry retaining walls: II. relevant parameters and analytical and numerical studies of real walls, Géotechnique 62 (2012) 10271040.

[30] A. ENTPE, Technique de construction des murs en pierre sèche : Règles professionnelles, MERICO, 2017.

[31] Association Française de Normalisation (AFNOR - French standard institute), NF EN 1998-1:2005 (eurocode 8) : Design of structures for earthquake resistance - part 1: General rules, seismic actions and rules for buildings, 2005 .

[32] B. des recherches géologiques et minières, "plan séisme : Le site internet de la prévention du risque sismique", http://www.planseisme.fr/Zonagesismique-de-la-France.html, Published the 20th January 2015, consulted the 24th september 2017.

\section{Appendix}

Table I: Reference acceleration $a_{g r}$ depending on the site.

\begin{tabular}{|c|c|c|}
\hline $\begin{array}{c}\text { Seismic } \\
\text { Area }\end{array}$ & Main geographic zones & $\begin{array}{c}a_{g r} \\
(\mathrm{~g})\end{array}$ \\
\hline 1 & North and South west of France & 0.04 \\
2 & Brittany and Central Massif & 0.07 \\
3 & Vosges, Jura and south of Loire's river & 1.1 \\
4 & Pyrénées and Alps & 0.16 \\
5 & Some overseas departments & 0.31 \\
\hline
\end{tabular}

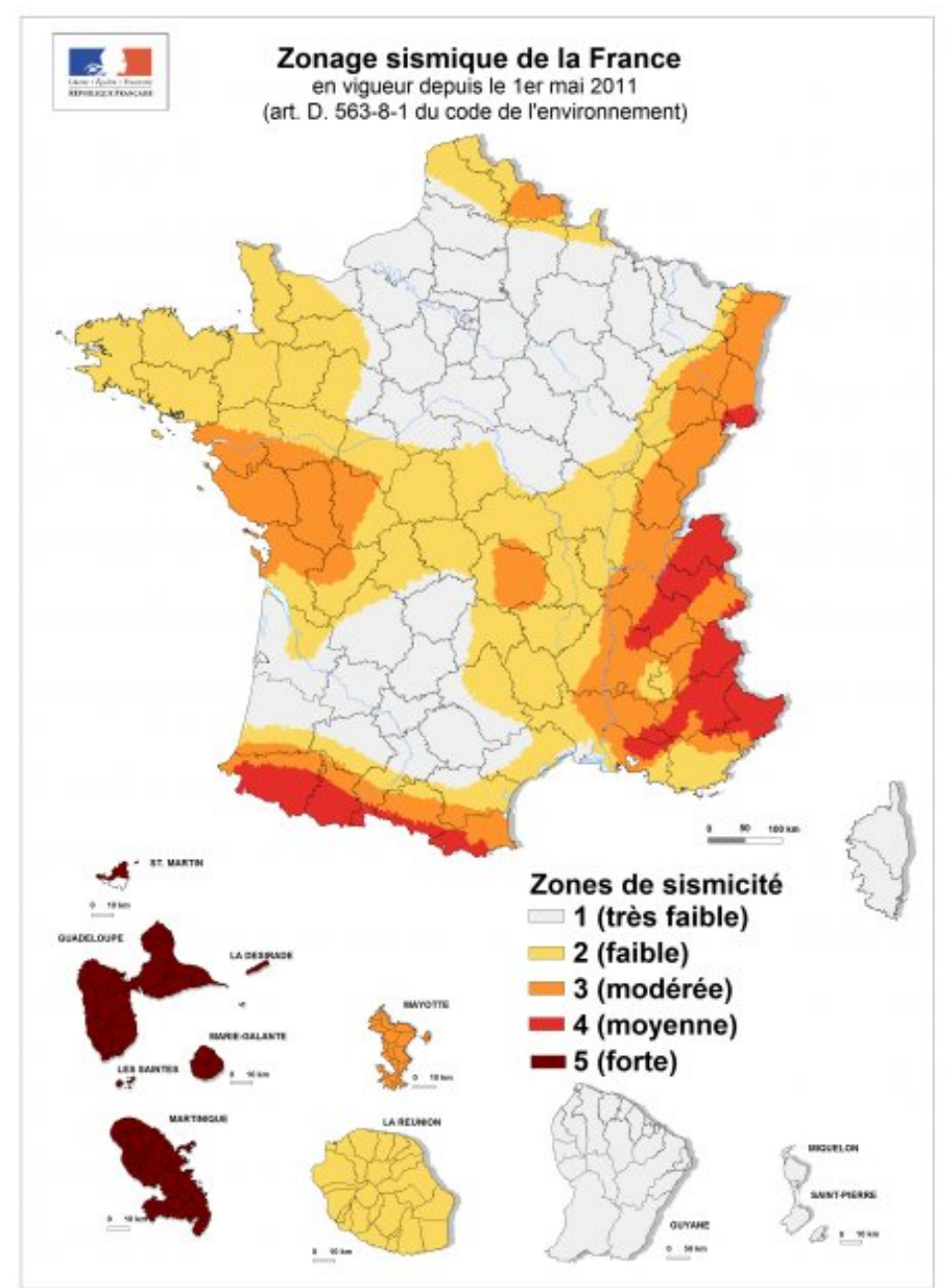

Figure I: Map of the seismic risk in France [32 
Table II: Different safety factors based on the consequences of the failure of a DSRW on the infrastructures in terms of the regional economics and number of casualties. Classification drawn the road construction guidance and the builduig construction guidance.

\begin{tabular}{|c|c|c|}
\hline $\begin{array}{c}\text { Class of } \\
\text { importance }\end{array}$ & Type of DSRWs & $\begin{array}{c}\text { Coefficient } \\
\gamma_{1}\end{array}$ \\
\hline I & $\begin{array}{c}\text { DSRWs built away from } \\
\text { homes and roads }\end{array}$ & 0.8 \\
\hline II & $\begin{array}{c}\text { DSRWs built near } \\
\text { homes and roads }\end{array}$ & 1.0 \\
\hline III & $\begin{array}{c}\text { DSRWs built near homes } \\
\text { bigger than 28 meter or } \\
\text { welcoming more than 300 people } \\
\text { or near highway, express } \\
\text { roads and railways }\end{array}$ & 1.2 \\
IV & $\begin{array}{c}\text { DSRWs built near hospital, } \\
\text { electricity facilities and } \\
\text { others buildings necessary } \\
\text { for the civil security }\end{array}$ & 1.4 \\
\hline
\end{tabular}

Table III: Effect of the foundation soil on the amplification of seismic acceleration.

\begin{tabular}{|c|c|c|}
\hline Class of soil & Type of soil foundation & Coefficient S \\
\hline A & Rock & 1 \\
B & Gravel, dense sand, stiff clay & 1.35 \\
C & sand, medium stiff clay & 1.5 \\
D & loose sand, low stiff clay & 1.8 \\
---------- & 1.6 \\
E & layer of soil C or D & \\
\hline
\end{tabular}

Table IV: Effect of the topography of the site on the amplification of the seismic acceleration.

\begin{tabular}{|c|c|}
\hline Topography of the site & Amplification coefficient $S_{T}$ \\
\hline Slope gentler than $15^{\circ}$ & 1 \\
Slope between $15^{\circ}$ and $30^{\circ}$ & 1.2 \\
Slope steeper than $30^{\circ}$ & 1.4 \\
\hline
\end{tabular}

Table V: Reducing factor $r$ depending of the capacity of the structure to move during the seismic motion.

\begin{tabular}{|c|c|}
\hline Capacity of displacement of the wall & $\begin{array}{c}\text { Reducing } \\
\text { factor } r\end{array}$ \\
\hline greater than $d(\mathrm{~mm})=300 * \alpha S$ (fraction of $\mathrm{g})$ & 2 \\
greater than $d(\mathrm{~mm})=200 * \alpha S$ (fraction of $\mathrm{g})$ & 1.5 \\
No significant displacement & 1 \\
\hline
\end{tabular}

